\title{
A FUNÇÃO DO ENSINO JURÍDICO PARA A FORMAÇÃO DO JURISTA DO SÉCULO XXI: UM RELATO DE EXPERIÊNCIA
}

\section{THE ROLE OF LEGAL TRAINING FOR THE DEVELOPMENT OF THE 21ST CENTURY LAWYER: NA EXPERIENCE REPORT}

\author{
Lilia Maria de Morais Sales ${ }^{1}$ \\ Gabriela Vasconcelos Lima² \\ Mateus Rodrigues Lins ${ }^{3}$
}

Recebido em: 01/06/2020 Aceito em: 27/07/2021

lilia@unifor.br gvasconceloslima@gmail.com mateusrlins@gmail.com

Resumo: $O$ presente estudo tem como objetivo analisar as habilidades necessárias para a formação de advogados no século XXI e apresentar tendências e diretrizes às lacunas do ensino jurídico nessa conjectura. Investigou-se, de forma crítica, a teoria de Howard Gardner acerca das inteligências múltiplas e a importância do ensino interdisciplinar para o desenvolvimento da criatividade e inovação no mercado de trabalho. Analisou-se como instituições de ensino superior como a IE University, Harvard, Stanford e a Fundação Getúlio Vargas Direito São Paulo estão integrando a dinamicidade do mercado jurídico às matrizes curriculares das graduações de seus cursos de direito. Verificou-se o comportamento dos escritórios jurídicos brasileiros frente às inovações tecnológicas e as mudanças que o mercado vivencia no século XXI com base em dados levantados pelo Centro de Ensino e Pesquisa em Inovação da FGV Direito São Paulo, conectando os indicadores aos desafios do ensino jurídico contemporâneo. Ao fim, conclui-se que a educação precisa ser pensada fora do modelo padronizado de ensino, valorizando inovações no espaço jurídico e viabilizando a criação de projetos de impacto. Apresenta-se, então, o programa Líderes que Transformam, implementado pela Pós-Graduação da Universidade de Fortaleza, um modelo curricular orientado à resolução de problemas reais por meio da apresentação de ações, projetos ou produtos, tendo como meio o desenvolvimento de competências. Acredita-se que os egressos deste modelo educacional, além de estarem preparados para ingressar e ascender profissionalmente no mercado de trabalho frente aos desafios do contexto atual, responderão às demandas sociais, atuando como cidadãos globais e lideranças em suas comunidades.

Palavras-chave: Ensino jurídico. Habilidades do Século XXI. Inteligências Múltiplas. Líderes que Transformam. Relato de Experiência.

\begin{abstract}
This study aims to analyze the skills needed to prepare lawyers for the 21st century and propose solutions to the legal education gaps. Through a critical perspective it was investigated the Howard Gardner theory of multiple intelligences and the importance of interdisciplinary for the development of creativity and innovation in the legal market. It has been analyzed how IE University, Harvard, Stanford and Fundação Getúlio Vargas Direito São Paulo are integrating the dynamicity of the legal market to curricular grades of law courses. Is was studied the behavior of brazilian law firms in front of technological innovations and the changes that the market is experiencing through the 21 st century by the data collected by the Center for Education and Research in Innovation at FGV Direito São Paulo, connecting the indicators to the challenges of the contemporary legal education. Finally, it concluded that education needs to be designed valuing innovations in the legal space and enabling the creation of impactful projects. The Líderes que Transformam program, implemented by the Postgraduate Program of the University of Fortaleza is then presented a curricular model aimed at solving real problems through the presentation of actions, projects or products, with the means or development of competencies. It is believed that the results of this educational model, in addition to prepare to enter and rise professionally in the job market wiil respond to social demands, designating the studants to acting as global citizens and leading in their communities.
\end{abstract}

Keywords: Legal training. 21st Century Skills. Experience Report. Leaders who Transform.

\footnotetext{
${ }^{1}$ Universidade de Fortaleza. Ceará. Brasil.

2 Universidade de Lisboa, Portugual/Universidade de Fortaleza. Ceará. Brasil.

${ }^{3}$ Universidade de Fortaleza. Ceará. Brasil.
} 
Multiple Intelligences.

\section{INTRODUÇÃO}

A velocidade da informação na sociedade contemporânea coloca à disposição do indivíduo milhares de links e palavras por dia. Atos cotidianos como enviar um e-mail, ligar um televisor, realizar pesquisas na internet ou até mesmo acender uma lâmpada transformam-se em dados que são armazenados com uma rapidez cada vez maior, devido ao fluxo contínuo com que estas informações são geradas (GOMES; BRAGA, 2017). Essa constatação produz efeitos ao espaço jurídico global que, gradativamente, busca inovações a fim de proporcionar uma operação condizente com a realidade social. Um exemplo é o robô ROSS, criado por pesquisadores da Universidade de Toronto e desenvolvido no Vale do Silício, que objetiva auxiliar advogados em pesquisas doutrinárias, legislativas e jurisprudenciais para a confecção de pareceres e peças processuais, num rápido espaço de tempo, a partir da compreensão de problemas reais e jurídicos os quais, também, são extensíveis à esfera administrativa (ROSS INTELLIGENTE, 2019, online).

Nesse campo, também se destacam as Legaltechs, startups voltadas à apresentação de soluções tecnológicas para o mercado jurídico com a finalidade de otimizar o tempo de advogados que trabalham em escritórios de advocacia ou em departamentos empresariais. Com o propósito de coleta, padronização e armazenamento de uma conjuntura de informações, elas eliminam os riscos da perda de dados importantes e auxiliam na produção de documentos e alerta de prazos, viabilizando uma colaboração intensa entre o direito e a tecnologia (SALES, BEZERRA, 2018). Para além desses aspectos, há Legaltechs que facilitam a comunicação com clientes e entre diferentes advogados, bem como há outras que viabilizam resoluções extrajudiciais de conflitos online. Originalmente denominadas Online Dispute Resolution (ODR), esse último tipo de Legaltech se divide em duas espécies essenciais, baseadas em diferentes aplicações tecnológicas, quais sejam: a) uso de algoritmos conexos às informações produzidas pelos envolvidos que, dentro de um sistema pautado pela lógica, os auxilia a chegarem a um resultado positivo para ambos; b) utilização de métodos já existentes e independentes da tecnologia, porém aplicados de forma online (PRADUROUX; PAIVA; CARO, 2016).

A modernização dos serviços jurídicos também viabilizou a promoção da quebra de monopólio acerca da gestão dos serviços jurídicos em países como a Inglaterra e o País de Gales que, por meio do Legal Services Act 2007, possibilitaram que atividades empresariais adstritas a outros segmentos de mercado também oferecessem esses serviços, inclusive, de forma especializada, retirando a exclusividade dos advogados (SALES, BEZERRA, 2018). Essa quebra, em certa medida, demonstra novas proporções de readaptações as quais o mercado jurídico necessitará enfrentar ao longo dos próximos anos.

Com isso, cabe observar que apesar de o termo "inovação" estar, muitas vezes, atrelado à tecnologia, ele deve ser compreendido como soluções novas e eficazes para as problemáticas já existentes. A inovação, nesse sentido, vai além do aspecto tecnológico e também abraça diferentes abordagens metodológicas e, acima de tudo, as habilidades humanas dos juristas que atuam em cada caso concreto. É exatamente essa condição que acentua a necessidade pela exploração de 
habilidades fundamentais e o desenvolvimento de inteligências múltiplas aos profissionais deste século. Por isso, a partir dos medidores do Times Higher Education (THE) e do Ranking Universitário da Folha de São Paulo (RUF), analisando as propostas de inovação desenvolvidas pelas escolas melhor ranqueadas, este artigo selecionou as universidades de Harvard e Stanford, nos Estados Unidos, IE Law School, na Europa e a Fundação Getúlio Vargas, no Brasil, a fim de verificar disciplinas e projetos desenvolvidos por estas instituições que conectam seus estudantes às mudanças do mercado jurídico. É a partir da análise destes modelos que a pesquisa busca responder a seguinte pergunta: frente ao tradicionalismo e estudos quase exclusivamente técnicos do ensino jurídico brasileiro, como os cursos de direito podem viabilizar uma aproximação dos estudantes com as evoluções profissionais no século XXI?

Com esta pesquisa, objetiva-se analisar as habilidades necessárias para a formação de profissionais do Direito no século XXI e propor soluções às lacunas do ensino jurídico nessa conjectura, apresentando, para isso, possíveis modelos de atividades educacionais. Nesse sentido, este texto se subdivide em três tópicos. No primeiro, discute-se o uso do ensino interdisciplinar como ferramenta essencial para o desenvolvimento das habilidades necessárias ao profissional do Século XXI. O segundo propõe uma breve análise acerca das inovações que estão ocorrendo no ensino jurídico, em um espaço global. E o último traça paralelos entre as necessidades averiguadas e propostas ao ensino jurídico, apresentando, então, o programa Líderes que Transformam, implementado pela Pós-Graduação da Universidade de Fortaleza, um modelo curricular orientado à resolução de problemas reais por meio da apresentação de ações, projetos ou produtos, tendo como meio o desenvolvimento de competências.

Ao fim, conclui-se que a educação precisa ser pensada fora do modelo padronizado de ensino, valorizando inovações no espaço jurídico e viabilizando a criação de projetos de impacto. Acredita-se que os egressos deste modelo educacional, além de estarem preparados para ingressar e ascender profissionalmente no mercado de trabalho frente aos desafios do contexto atual, responderão às demandas sociais, atuando como cidadãos globais e lideranças em suas comunidades.

\section{INTERDISCIPLINARIEDADE COMO ESTÍMULO À CRIATIVIDADE E SUPORTE À INOVAÇÃO NO MEIO JURÍDICO}

Para que serve a educação? Ken Robinson (2019) apresenta essa pergunta como a questão fundamental para compreender o processo educacional dentro de suas funções múltiplas, tendo em vista que assim como a democracia e a justiça, a educação é um conceito que merece constante reflexão. Não há resposta objetiva à indagação, pois ela está dentro de variáveis culturais, étnicas, religiosas, subjetivas ou mesmo atrelada a peculiaridades sociais e, portanto, deve ser respondida de acordo com a percepção de cada povo que interage com o sistema educacional, possuindo a busca pelo desenvolvimento humano como ponto de convergência (SEN, 2010). No entanto, em que medida o sistema educacional aproxima e afasta sujeitos da real compreensão de desenvolvimento? O que significa desenvolvimento para o sistema educacional? 
Há na educação, desde a perspectiva fundamental, um sistema de ensino padronizado que parece imutável ao espaço-tempo. Este sistema, herdado a partir da conjuntura da produção em massa à época da Revolução Industrial, demonstra uma preocupação da escola em preparar crianças para a realização de atividades básicas de escrita, leitura e matemática para que possam ingressar no ensino médio e, em seguida, acessarem o ensino superior e se tornarem funcionários capazes de girar a roda econômica do país (ROBINSON, 2019). A crítica que Ken Robinson (2019) traça a esse processo é que ele não é capaz de explorar as reais inteligências e talentos das pessoas que acessam o ensino e, com isso, transforma a educação, em alguns casos, em um espaço desestimulante. Os alunos não são mais ou menos inteligentes que outros, mas sim, possuem habilidades diferentes que precisam ser desenvolvidas e exploradas o que não acontece num sistema padronizado de ensino.

Nesse sentido, Howard Gardner (2010) teorizou nove tipos de inteligência comuns a todos os seres humanos, quais sejam: a linguística (uso das palavras para fórmulas de expressão), lógicomatemática (quantificação de coisas, levantamento de hipóteses e comprovações lógicas), musical (discernimento entre sons, ritmos e timbres), espacial (ampla visualização do espaço geográfico), corporal-cinestésica (coordenação entre corpo e mente), interpessoal (desenvolvimento de empatia), intrapessoal (compreensão de desejos e sentimentos próprios), naturalista (leitura e conexão ampla com a natureza) e a existencial (compreensão do mundo para além de nossa percepção física). Das constatações da teoria de Howard, elencadas em sua obra Frames of Mind: The Theory of Multiple Intelligences ${ }^{4}$, observa-se que por mais que as pessoas possuam semelhanças ou, até mesmo, tenham irmãos gêmeos, suas inteligências terão características diferentes em razão das experimentações ao longo da vida. Portanto, cada indivíduo é único em razão de sua compreensão intelectiva e vivências de mundo.

Com base na teoria de Howard, observa-se que o sistema educacional tende a valorizar o desenvolvimento das inteligências linguística e lógico-matemática, afastando-se das outras sete. Esse movimento se replica em escala mundial. Um exemplo é a forma de avaliação e, consequentemente, os resultados apresentados pela tabela de classificação do Programme for International Student Assessment ${ }^{5}$ (PISA). O PISA, sob coordenação da Organisation for Economic Co-operation and Development ${ }^{6}(\mathrm{OECD})$, analisa o desenvolvimento escolar das nações com base em testes de leitura, matemática e ciências que são realizados com jovens de quinze anos de idade. Os exames ocorrem a cada três anos ${ }^{7}$ e preservam o intuito de oferecer ferramentas às políticas públicas educacionais de cada país (OECD, 2020). A execução e implicações deste teste na estrutura político-econômica dos países que o realizam, reforça a crítica que Paulo Freire (1987) faz ao caráter paternalista do ensino expositivo e, portanto, padronizado, definindo-o como uma estratégia de ensino que tende a anular ou minimizar o poder criador dos estudantes, servindo como um estímulo em escala para que muitos alunos permaneçam na ingenuidade de sua zona intelectiva. De tal forma, a uniformização educacional influencia não apenas a forma de ensino, mas o modo como os sujeitos

\footnotetext{
4 Tradução livre: Estruturas da Mente - A Teoria das Inteligências Múltiplas

5 Tradução livre: Programa Internacional de Avaliação de Alunos

6 Tradução livre: Organização para Cooperação e Desenvolvimento Econômico

7 No site http://www.oecd.org/pisa/ é possível conferir os resultados do último exame que ocorreu em 2018.
} 
constroem currículos, compreendem o mundo e avaliam uns aos outros nos espaços sociais. Isso contribui para um comportamento massificado que tende a afastar a busca por inovações não apenas do espaço educacional, mas de todos os campos que compreendem a vida comunitária.

Em termos de políticas públicas ou mesmo sob a óptica das instituições privadas, a evasão escolar em razão da não adequação do aluno com a proposta de ensino não é vista como um problema do sistema educacional, mas sim do aluno (ROBINSON, 2019). A queda dos padrões escolares acaba sendo percebida como uma ausência de competitividade e responsabilidade dos estudantes, o que passa a ser extremamente prejudicial ao desenvolvimento de alunos que não conseguem se adequar ao sistema de ensino. Na óptica do nível superior, a ideia de competitividade e responsabilidade, em especial compreendidas na iminência do ingresso ao mercado de trabalho, contribuem com o surgimento de problemas como a elevação do nível de estresse, depressão e, em casos extremos, tornam-se causas de suicídio (VICTORIA et al., 2013).

Steve Ress, um arquiteto da cidade de Kansas, foi convidado para falar sobre sua carreira durante um almoço na DeLaSalle Education Center, uma escola de ensino médio que atendia jovens com passados problemáticos ou que haviam sido expulsos de outras escolas. Durante a sua fala, Steve percebeu que muitos dos jovens tinham enormes potenciais, mas que ainda não haviam se enquadrado ao sistema escolar. Diante da constatação, optou por tomar uma posição mais ativa no processo de aprendizagem desses alunos e inaugurou um projeto que mesclava criatividade e empreendedorismo voltado à projeção de carros. O projeto intitulado Minddrive cresceu, recebeu patrocínios importantes, como o da marca Bridgstone, e os alunos passaram a oferecer palestras em diferentes cidades, comentando sobre seus feitos e invenções. Atualmente, Minddrive conta com um corpo de pessoas empenhadas em geri-lo, devido às proporções que tomou (MINDDRIVE, 2019). O projeto de Ken Ress foi capaz de viabilizar uma transformação em alunos desacreditados que o sistema educacional padronizado jamais conseguiria atingir sem valorizar o pensamento criativo conexo às áreas não técnicas.

O Fórum Econômico Mundial, em seu relatório mais recente acerca do futuro dos empregos, classifica as habilidades do século XXI em grau de importância, da seguinte forma: 1) Resolução de problemas complexos; 2) Pensamento crítico; 3) Criatividade; 4) Gestão de pessoas; 5) Interação com outros indivíduos; 6) Inteligência emocional; 7) Tomada de decisões; 8) Orientação de serviços; 9) Negociação; 10) Flexibilidade cognitiva (WORLD ECONOMIC FORUM, 2018). Esses dados demonstram que, futuramente, o trabalho repetitivo será gradativamente realizado por inteligências artificiais e que os profissionais do século XXI deverão ter um perfil mais conectado ao uso da imaginação e do agir humano para propor soluções a problemas mutáveis. Trabalhos coletivos terão valorização maior que individuais, por estarem atrelados a uma pluralidade de habilidades e inteligências múltiplas. Questões como empatia, liderança, adaptabilidade, tomada de decisões, empoderamento do outro, autonomia e facilidade para conexões interpessoais passarão a ser mais notáveis no ambiente de trabalho. A capacidade de atrelar processos criativos à prática profissional será um dos principais fatores de desenvolvimento laboral deste século, pois será ela que diferenciará o trabalho humano do automatizado e promoverá inovações aos diferentes setores da política, sociedade e do mercado. 
Dessa forma, a ideia de desenvolvimento, se compreendida como um processo de expansão das liberdades instrumentais (SEN, 2010), brevemente se tornará insustentável dentro do panorama de um sistema de ensino padronizado. Essa proposta educacional distancia os sujeitos de uma aproximação com as habilidades do Século XXI, formando profissionais com criatividade limitada para enfrentarem os problemas das próximas décadas (WALDMAN; DALPIAN, 2017). São necessárias mudanças no sistema de ensino, mas que devem ser realizadas de forma gradativa, cautelosa e frente a planejamentos estruturais, compreendendo do ensino fundamental ao superior. Todavia, de imediato, o ensino superior, em especial, as universidades, por conectarem todas as áreas do conhecimento humano, apresenta-se como o espaço ideal para o desenvolvimento criativo no ensino, promovendo o acesso às habilidades do Século XXI por meio de um ensino interdisciplinar (WALDMAN; DALPIAN, 2017). A interdisciplinaridade identifica um caminho inicial a ser percorrido exatamente por promover o encontro do estudante não apenas com outros cursos ou áreas de conhecimento, mas consigo mesmo enquanto indivíduo e por focar o desenvolvimento das inteligências múltiplas para o encontro das habilidades deste século potencializando uma construção curricular mais condizente com a realidade social (COUTINHO et al, 2017). É nesse âmago que o curso de direito, frente às mudanças que estão impactando o mercado jurídico, precisa direcionar a formação de seus discentes.

\section{PROPOSTAS EDUCACIONAIS PARA O SÉCULO XXI}

A partir dos medidores do Times Higher Education (THE) para o ano de 2020 e do Ranking Universitário da Folha (RUF) do ano de 2019, foram selecionadas quatro instituições que apresentam programas de ensino atrelados à metodologias ativas que estimulam a criatividade dos alunos e a interdisciplinaridade, contribuindo com 0 desenvolvimento das habilidades essenciais aos profissionais deste século. Foram analisadas as contribuições da IE University, 33a colocada em termos de ensino no ranking europeu do THE (2019), Universidade de Stanford, $4^{\text {a }}$ colocada no ranking mundial do THE (2020), Universidade de Harvard, $7^{\text {a }}$ colocada no ranking mundial do THE (2020) e da Fundação Getúlio Vargas de São Paulo, 3ª colocada no RUF (2019).

A IE Law School, escola de direito da IE University (Espanha), integra valores do empreendedorismo, gestão, inovação, tecnologia, finanças, humanidade e diversidade. Apresenta-se como uma instituição vanguardista, oferecendo programas como o Lawahead Hub, Legaltech Innovation Farm e o Global Legaltech Venture Days, além de viabilizar graduações conexas com outras áreas, como direito e relações internacionais; direito e administração de empresas; políticas, direito, economia e análise de dados e negócios (IE, 2019).

O Lawahead Hub é um ecossistema colaborativo e aberto, desenvolvido para firmas jurídicas, escolas de direito, empresas e juristas, com a finalidade de explorar causas e consequências das profundas transformações que estão tomando espaço na educação, profissões jurídicas e no sistema jurídico global (IE, 2019). Ele é um instrumento essencial para a construção e prototipagem de produtos educacionais que a instituição se propõe a oferecer. 
Desenvolvido em conjunto com os polos de ciências e de tecnologias inovadoras, a Legaltech Innovation Farm desenha-se como um laboratório neutro-tecnológico para criar e incubar experimentações que conectem tecnologia e direito. Trabalhando com lideranças corporativas do mundo jurídico, o projeto prototipa aplicativos, produz softwares e modelos de negócios jurídicos (IE, 2019). A proposta se conecta ao Global Legaltech Venture Days que corresponde a um evento anual promovido pela instituição desde 2018 com o intuito de promover uma seleção de legaltechs inovadoras espalhadas pelo globo, oferecendo espaço de implementação e desenvolvimento no campus da universidade para as que forem melhor avaliadas (IE, 2019).

Além da IE University, as universidades de Harvard e Stanford incluíram nas grades dos seus respectivos cursos de direito, disciplinas voltadas ao desenvolvimento das habilidades do Século XXI. Em Harvard (Estados Unidos), destacam-se programas como Law Without Walls ${ }^{8}$, Problem Solving Workshop ${ }^{9}$, Legal Research and Writing Program ${ }^{10}$ e o Law and Bussiness ${ }^{11}$, que viabiliza a integração das disciplinas atinentes aos cursos de direito e de administração da instituição, possibilitando que juristas aprendam sobre estratégias negociais e desenvolvimento de liderança (SALES, BEZERRA, 2018).

Law Without Walls tem por finalidade treinar juristas para a resolução criativa de conflitos, desenvolvendo empatia, aptidões interdisciplinares e a capacidade de comunicação que, na disciplina, decorre dos trabalhos fomentados em equipe (SALES, BEZERRA, 2018). O Problem Solving Workshop proporciona conexões entre o estudo acadêmico e o prático, ocasião em que os estudantes poderão refletir, dentro de um espaço colaborativo, acerca dos problemas com os quais advogados lidam em seu cotidiano, perpassando pelas etapas de construção intelectual, composição de estratégias para atingir os objetivos do cliente dentro dos limites legais e obtenção de soluções (HARVARD UNIVERSITY, 2019). Já o Legal Research and Writing Program utiliza uma série de escritos, pesquisas acadêmicas e peças jurídicas para proporcionar uma imersão do estudante ao processo de raciocínio jurídico, colaborando com a compreensão ampla de problemas e com o desenvolvimento da capacidade argumentativa e análise estrutural das situações (HARVARD UNIVERSITY, 2019).

No que toca à Universidade de Stanford (Estados Unidos), nota-se uma matriz curricular voltada a um contato interdisciplinar em que o aluno possui autonomia para a construção de seu caminho universitário, a partir da seleção de disciplinas (UNIVERSITY OF STANFORD, 2019). Com disciplinas que abordam contextos tecnológicos, estimulam a tomada de decisão, competências de gestão, percepções psicológicas do indivíduo e técnicas de negociação e mediação, destacam-se as disciplinas de Legal Research and Writing ${ }^{12}$ e Law and Creativity ${ }^{13}$ (SALES, BEZERRA, 2018).

As capacidades de síntese, interpretação ampla e estrita ao texto, bem como a escrita de impacto para pesquisas e peças jurídicas estão atreladas à disciplina de Legal Research and Writing

\footnotetext{
8 Tradução livre: Direito sem barreiras

9 Tradução livre: Oficina de solução de conflitos

10 Tradução livre: Programa de pesquisa jurídica e escrita

11 Tradução livre: Pesquisa jurídica e escrita

12 Tradução livre: Direito e Criatividade

13 Tradução livre: Direito e Negócios
} 
(UNIVERSITY OF STANFORD, 2019), a qual demonstra relevância ao desenvolvimento material e estético de um trabalho escrito, o que está intimamente conectado às ferramentas de criatividade do aluno, vez que a elaboração e a interpretação subjetiva de um texto, jurídico ou não, decorre de um processo criativo (LEVÝ, 1971). Quanto à disciplina Law and Creativity, ofertada em formato de workshop de escrita criativa, há o estudo da legislação como um processo criativo. A proposta aproxima direito e arte por meio do pensamento criativo com o auxílio de mídias variadas para, em seguida, sistematizar produções coletivas em formato escrito, ficcionais ou não, de forma que possam ser debatidas em grupo ao final da disciplina (UNIVERSITY OF STANFORD, 2019).

No Brasil, a Fundação Getúlio Vargas (FGV-SP), por meio de sua escola de direito, rompe com o ensino tradicional ao adotar uma metodologia participativa, capaz de colocar o aluno como construtor do próprio conhecimento. Essa proposta repercute na estruturação da matriz curricular que trabalha a compreensão do direito sempre em uma perspectiva atual. Em meio a ela, a disciplina Incita: liderando mudanças positivas em biotecnologia se destaca como uma inovação metodológica, baseada na experimentação, que atrela direito, tecnologia e biologia ao longo de uma semana de imersão em que os alunos irão trabalhar desenvolvimento de liderança, baseados em sete competências fundamentais, como a criatividade, comunicação, cooperação, capacidade crítica, consciência de si, consciência social e cultura digital (FGV, 2020).

A elaboração o currículo e a construção das disciplinas da Escola de Direito da Fundação Getúlio Vargas perpassa por alguns núcleos de pesquisa da instituição, dentre os quais se destacam o Observatório do Ensino do Direito (OED) e o Centro de Ensino e Pesquisa em Inovação (CEPI), ambos atrelados ao Núcleo de Metodologia de Ensino (NME) da FGV. O primeiro coleta, organiza e divulga informações sobre o ensino jurídico brasileiro com a finalidade de discutir estratégias metodológicas de formação dos alunos e sua inserção no mercado de trabalho, enquanto o segundo estrutura pesquisas correlacionando metodologias de ensino, tecnologia e o desenvolvimento das habilidades profissionais para o século XXI (FGV, 2020). O CEPI é o núcleo responsável pela prototipagem de novas disciplinas, as quais são experimentadas de forma gradual, fragmentando a mudança cultural que representam a partir de resultados obtidos com os próprios alunos (FGV, 2020).

As propostas metodológicas interdisciplinares desenvolvidas pela FGV, IE University, Havard e Stanford são resultado de pesquisas não apenas no campo educacional, mas também dos mercados atrelados ao espaço geográfico em que estão inseridas. Justamente pela questão geográfica, elas não devem ser tomadas como modelos a serem fielmente seguidos, isso porque cada proposta está atrelada a uma conjuntura social, cultural e educacional particular, o que não necessariamente implica que terão o mesmo resultado se replicadas em outra localidade, exatamente porque as demandas de outro ambiente serão diferentes. De tal modo, a inovação não pode ser importada completamente pronta, mas redesenhada de acordo com o que cada comunidade busca e anseia enquanto mercado ou sistema educacional. Ela precisa de modulações para ser aplicada, perpassando por questionamentos como "a comunidade de determinado lugar está preparada para receber determinado tipo de inovação?"; "se não estiver, como prepará-la?"; "a comunidade quer passar por essa inovação?"; "quais são as necessidades da localidade em que se pretende implementar uma inovação educacional?"; “como atendê-las?”. Essas perguntas operam como os 
primeiros guias à compreensão de que cada espaço caminha em seu ritmo de mercado e isso não significa, obrigatoriamente, que eles são atrasados, mas apenas que ainda não identificaram certa demanda. Nesse sentido, a inovação e a criatividade devem estar voltadas às necessidades de determinado sistema e mercado ao qual se pretende abranger e deve perpassar, antes de tudo, por uma compreensão ampla da sociedade a se atingir, bem como da cultura por ela desenvolvida.

A partir dessa conjuntura, alinha-se criatividade e ciência jurídica para o desenvolvimento de metodologias educacionais capazes de transcender ao conhecimento teórico ou ao modelo puramente expositivo criticado por Paulo Freire, dando aptidão ao aluno para guiar seu próprio aprendizado e causar impacto por meio de seu raciocínio e suas ações. Com isso, nota-se que as universidades tradicionais precisam encontrar caminhos para reconfigurar seus modelos de ensino e, aos poucos, apresentarem inovações capazes de atender às demandas sociais causadas pelo século XXI, dentro do recorte social, cultural e de mercado ao qual estão inseridas (CHRISTENSEN; EYRING, 2014).

\section{ENSINO JURÍDICO E A PREPARAÇÃO DO PROFISSIONAL DO DIREITO PARA OS DESAFIOS DO SÉCULO XXI: RELATO DE EXPERIÊNCIA DO PROGRAMA LÍDERES QUE TRANSFORMAM}

Em dezembro de 2018, o Centro de Ensino e Pesquisa em Inovação (CEPI) da FGV Direito São Paulo, publicou os resultados de uma pesquisa de caráter quantitativo e de outra pesquisa de caráter qualitativo acerca do futuro das profissões jurídicas, em que elegeram escritórios de advocacia como representantes da área jurídica devido ao número de advogados registrados na Ordem dos Advogados do Brasil (OAB), bem como ao elevado grau de pressão de mercado que a função sofre. A pesquisa intitulada “O futuro das profissões jurídicas: você está preparad@?”, em sua natureza quantitativa, buscou mensurar em que medida os escritórios estão preparados para uma advocacia pautada nos avanços tecnológicos, tendo por amostragem escritórios das cinco regiões do Brasil, dos quais, 109 pertencem à lista dos 500 escritórios mais admirados do país (CEPI, 2018). A partir de entrevistas, a pesquisa chegou aos seguintes resultados: há desigualdades significativas no uso da tecnologia por escritórios de grande porte e de pequeno porte; atualmente, o uso de ferramentas tecnológicas contemplam apenas organização e cadastro de informações; existe amplo espaço para que ferramentas tecnológicas sejam implementadas, frente às atividades de alta repetitividade dentro dos escritórios de advocacia (CEPI, 2018).

Em meio às conclusões da pesquisa quantitativa, a informação de maior relevância que se pode extrair é a de que os escritórios de advocacia não estão preparados para atuarem com base em tecnologias computacionais avançadas. Contudo, os dados revelam um movimento crescente na reformulação dos escritórios para uma readequação às novas perspectivas sociais a partir da contratação de serviços de TI, uso de softwares para gestão processual e financeira, uso de softwares para o auxílio em atividades jurídicas e o desenvolvimento de setores responsáveis pelo gerenciamento do conhecimento e dos documentos produzidos pelos escritórios (CEPI, 2018).

Em sua natureza qualitativa, a pesquisa obteve quatro diferentes conclusões: as características do modelo contencioso de advocacia estimulam a adoção de soluções tecnológicas; 
existe um processo de substituição de tarefas realizadas pelos profissionais da área jurídica, as quais se concentram em cargos de baixa hierarquia organizacional ou em atividades de suporte; profissionais de diferentes áreas estão sendo contratados para compor equipes em escritórios de advocacia; novos arranjos organizacionais estão sendo desenhados devidos às implementações tecnológicas na advocacia (CEPI, 2018).

No que tange à primeira conclusão da pesquisa, observou-se que a pressão de clientes, os custos da gestão de processos, a alta repetição de argumentos jurídicos na produção das peças processuais suscetíveis ao erro humano e a necessidade de otimizar a visualização de processos e produção de relatórios para clientes, reforçam o argumento de que máquinas deverão realizar atividades repetitivas em escritórios de advocacia, deixando aos advogados a execução de tarefas que requeiram um pensar mais complexo e um agir mais humano, o que converge com as questões levantadas pela segunda conclusão da pesquisa qualitativa (CEPI, 2018). A substituição de advogados por máquinas, de acordo com o levantamento do CEPI atinge os cargos hierarquicamente mais baixos exatamente em razão da atividade desenvolvida pelos profissionais que ocupam as posições de risco. Essa reconfiguração do modelo de trabalho e da estrutura organizacional dos escritórios modernos contribui para a absorção de profissionais de outras áreas, em razão da necessidade de inovar e, portanto, agir de forma interdisciplinar dentro dos serviços jurídicos ofertados. A terceira conclusão da pesquisa aponta profissionais da engenharia de produção, ciências da computação, administração, letras, estatística, ciência política, matemática e profissionais híbridos (com duas formações) como pessoas capazes de otimizar a performance dos escritórios no que toca à gestão, produtividade, distribuição de trabalho, apresentação de serviços e desenvolvimento de estratégias. Desse modo, a interdisciplinaridade fomenta a quarta e última conclusão da pesquisa, a qual se volta à integração de novas tecnologias capazes de desempenhar atividades de excelência. Dentre essas tecnologias, aponta-se a incubação de lawtechs em escritórios de advocacia, acordos de cooperação mútuos entre os escritórios e legaltechs, tal como pesquisas para desenvolvimento tecnológico em setores internos aos escritórios de advocacia (CEPI, 2018).

A análise aos indicadores da pesquisa do Centro de Ensino e Pesquisa em Inovação da FGV Direito São Paulo norteiam a direção do mercado da advocacia brasileira para as próximas décadas e estimulam o pensar acadêmico para a formação de futuros advogados. De acordo com o guia framework de inovação para instituições de ensino superior levantado pela SEMESP no ano de 2018, a educação perpassa um caminho híbrido para se conectar ao mercado, abraçando aspectos pedagógicos e gerenciais. Gerencial porque o movimento de inovação gera resistência e, desse modo, as instituições de ensino devem trabalhar processos internos, de forma gradativa, para abrir caminhos ao desenvolvimento de programas e disciplinas voltados à formação de profissionais com habilidades do século XXI (SEMESP, 2018). Com isso, o framework aponta um caminho de mudança de comportamento mental nas instituições educacionais que perpassa por um diálogo corporativo, seguido pelo estudo e proposição de projetos, validação das experimentações, implementação do processo de inovação, feedbacks dos testes realizados, avaliação e compartilhamento dos resultados com gestores e investidores das inovações (SEMESP, 2018). 
O caminho educacional, para isso, deve estar conectado ao mercado que pretende servir, conhecer suas demandas locais, exigências futuras e direcionar os alunos para a melhor exploração possível da profissão. Na era tecnológica em que máquinas começam a realizar trabalhos repetitivos dentro de escritórios de advocacia, destaca-se o profissional que dominar competências exclusivamente humanas como a capacidade criativa, o trabalho em equipe e a resolução de problemas complexos, as quais são habilidades do século XXI. Para isso é necessário que a instituição de ensino conheça o seu público, compreenda que cada aluno possui experiências anteriores à sala de aula e que essas vivências irão integrar o processo de aprendizado, conectem as propostas de ensino às questões que fazem parte do cotidiano de seus estudantes por meio de metodologias ativas, apresentem um mapeamento de mercado e proporcionem uma compreensão das mudanças tecnológicas e sistêmicas pela qual ele passa, bem como, estimulem os alunos a desenvolverem atividades que os robôs não fazem, trabalhando o agir humano.

Com base nessas diretrizes, no ano de 2012, na cidade de Fortaleza, Estado do Ceará, a Pós-Graduação da Universidade de Fortaleza (Pós-Unifor) passou por um processo de reflexão e redirecionamento de seus currículos como forma de contribuir para a formação de profissionais capazes de responder às demandas do mercado e da sociedade no contexto do século XXI.

Ao analisar os dados apresentados nas seções anteriores, o grupo gestor redesenhou o propósito da Pós-Unifor, que passou a ser o de desenvolver cidadãos globais capazes de impactar positivamente a sociedade ou, resumidamente, formar lideranças que transformam realidades. Desenhou-se o programa Líderes que Transformam sustentado sobre três pilares: 1) o desenvolvimento das habilidades necessárias ao profissional do século XXI; 2) a qualificação técnica de excelência; 3) transferência do conhecimento por meio de ideias, ações, projetos e produtos que impactem positivamente a sociedade.

Estes pilares foram adotados para todos os cursos de todas as áreas do conhecimento. Estes cursos, no entanto, foram agrupados em Escolas, de acordo com as áreas. quais sejam: Direito, Gestão e Comunicação, Tecnologia e Saúde. Para os fins deste artigo, realizar-se-á o relato de experiência do programa Líderes que Transformam para a Escola do Direito.

Quanto ao primeiro pilar, o desenvolvimento das habilidades do século XXI, todas as Escolas idealizaram um núcleo de disciplinas comum a todos os cursos, que visam despertar nos estudantes habilidades como resolução de problemas complexos, criatividade, comunicação, trabalho em equipe, visão sistêmica, pensamento crítico, gestão de conflitos e gerenciamento de projetos. As disciplinas idealizadas para a Escola de Direito foram as seguintes: Marketing Jurídico, Argumentação Jurídica, Senso de Justiça e Tomada de Decisão, Gestão de Conflitos, Legal Design e Elaboração e Gerenciamento de Projetos.

O desenvolvimento destas habilidades é percebido como importante pelos estudantes, que relatam ter aprendido "[...] que a gente precisa efetivamente buscar soluções criativas para problemas comuns do nosso cotidiano" (UNIFOR, 2019, p. 47) ${ }^{14}$.

14 Depoimento concedido pelo aluno do Mestrado Profissional em Direito e Gestão de Conflitos, Wilson Sales Belchior. 
Este núcleo de disciplinas ocorre em salas de aula que reúnem até 150 (cento e cinquenta) alunos que trabalham prioritariamente em equipes durante aulas ministradas com a adoção de metodologias ativas, como forma de promover experiências que contribuam para a construção das habilidades supramencionadas. O corpo docente deste núcleo atua de maneira coordenada, de forma a alinhar os objetivos de aprendizagem, conteúdos, metodologias adotadas e atividades realizadas em sala. Assim, privilegia-se a formação de conexões entre os alunos e a promoção de experiências significativas para os alunos.

A aluna Simone Mayara Ferreira, por sua vez, lembra do momento exato em que o seu trabalho iniciou, durante uma das disciplina deste núcleo comum, que objetiva desenvolver as habilidades de criatividade, visão sistêmica, trabalho em equipe e gerenciamento de projetos: "Eu, com uma equipe de cinco amigos, tinha que pensar em alguma coisa exequível na nossa área e inovadora. Então, desenhamos um escritório de advocacia que atenderia imigrantes impossibilitados de arcar com esse tipo de atendimento. Era uma ideia simples, que parecia possível. Em seguida, nós tivemos uma disciplina sobre direito dos refugiados e foi aí que calhou perfeitamente. A professora Camilla já trabalhava como voluntária nesse tipo de assessoria específica para refugiados. Então, com a ajuda dela e do coordenador do curso, colocamos o projeto para funcionar em uma estrutura que já existia dentro da Pastoral do Migrante" (UNIFOR, 2019, p. 82).

Quanto ao segundo pilar, que visa promover uma qualificação técnica de excelência, prima pelo desenho e implementação de matrizes curriculares de cada área técnica que contribuam para a construção de conhecimento técnico pautado na vanguarda das áreas específicas. Para tanto, promove-se networking dos alunos com profissionais de destaque no mercado de trabalho, em eventos que objetivam a promoção do diálogo entre eles, além de aulas de campo, visitas técnicas e missões nacionais e internacionais, como forma inserir os alunos Pós-Unifor em contextos inovadores do mercado jurídico.

Cada um dos pilares do programa Líderes que Transformam é fundamental para a concretização do objetivo final. No entanto, o terceiro pilar representa a realização efetiva deste, pois por meio dele o aluno assume protagonismo identificando problemas reais e idealizando e, preferencialmente, implementando soluções, que venham a transformar positivamente a sociedade. Estes projetos, ações e produtos são apresentados como o Trabalho de Conclusão de Curso (TCC) e devem contribuir direta ou indiretamente para a consecução dos Objetivos do Desenvolvimento Sustentável (ODS), da Organização das Nações Unidas ${ }^{15}$.

Desde a implementação do programa Líderes que Transformam, dezenas de ações foram realizadas por alunos da Escola de Direito, dentre eles, menciona-se: 1) a criação de aplicativo de online dispute resolution, adotando estratégias de negociação, visando a eficientização da solução de

15 Os Objetivos do Desenvolvimento Sustentável fazem parte da Agenda 2030 da Organização das Nações Unidas (ONU), consistindo em um acordo firmado pelos Estados-membro, com o objetivo principal de erradicar a pobreza do mundo. Em razão dessa proposta pedagógica o Pós-Unifor obteve, em 2019, o reconhecimento da ONU como boa prática para a concretização dos ODS, com possibilidade de ser replicada por outras instituições que desejam fomentar o potencial de transformação social em seus estudantes, por meio de uma educação de qualidade. Informações sobre este reconhecimento podem ser acessadas em: https://sustainabledevelopment.un.org/partnership/?p=31002. 
conflitos eminentemente patrimoniais; 2) a implementação do aplicativo mencionado em vara de comarca do interior do estado do Ceará, como forma de aprimorar a prestação jurisdicional, solucionando conflitos de maneira mais rápida e adequada; 3) por meio da adoção de estratégias de construção de consensos, um aluno conseguiu a solução, em dois anos, de ação trabalhista do estado do Ceará, que durava mais de 30 anos e beneficiou mais de 1.000 professores aposentados; 4) a criação de centro de mediação, visando a solução de dívidas de idosos superendividados; 5) a implementação de programa de assessoria jurídica para imigrantes e orientação para inclusão social e no mercado de trabalho brasileiro; 6) a execução de projeto de gestão de conflitos com idosos internos em lar de idosos, na cidade de Fortaleza; 7) a criação de plataforma de digital como ferramenta de resolução de conflitos e otimização na prestação de serviços públicos de saúde, com o objetivo de desburocratizar e tornar mais eficiente os processos de judicialização da saúde no estado do Ceará; 8) o desenvolvimento de plataforma, visando compilar dados para o gerenciamento de penas alternativas para a formação de um repositório de informações que possam servir como parâmetros para as varas criminais de todo o País; 9) o desenvolvimento de plataforma de online dispute resolution voltada para demandas repetitivas de grandes corporações e, principalmente, bancos; 10) a execução de projeto que uniu arte e o desenvolvimento de habilidades em gestão de conflitos, por meio da criação e realização de um espetáculo musical, em jovens em situação de vulnerabilidade social, como forma de efetivação do direito à educação.

Por meio do desenvolvimento destes projetos, percebe-se que os alunos se tornam não só profissionais adequados ao mercado de trabalho atual, mas, sobretudo, se tornam cidadãos mais conscientes de seu papel social e de seus potenciais enquanto agentes de transformação. Nas palavras de João Renato, o programa Líderes que Transformam "[...] me fez enxergar coisas que eu não conseguia. A partir daí, comecei a enxergar que muitas das coisas não eram meros devaneios, pois se a gente conseguisse construir um projeto embasado, a gente conseguiria chegar a lugares nunca antes alcançados".

Estes alunos indicam que o suporte da Universidade foi fundamental para não só motivá-los a transformar realidades, mas sobretudo para fornecer os instrumentos necessários para a implementação dos projetos que, antes, eram palavras em papel ${ }^{16}$.

Os projetos, produtos e ações apresentados, juntamente aos relatos compartilhados pelos alunos fortalecem a percepção de que este modelo educacional participativo, onde o aluno passa a ser o centro, o respeito às suas potencialidades é fortalecido e o estímulo ao desenvolvimento das competências transversais apontadas como de grande importância para o século XXI, especialmente diante do avanço tecnológico, passa a apresentar respostas às necessidades da sociedade e do mercado de trabalho. Consolida-se, assim, uma formação com propósito de ser vetor de inclusão e transformação, com foco no impacto positivo para a sociedade.

\footnotetext{
16 Depoimentos dos alunos concedidos em vídeo disponível no link: https://www.youtube.com/watch?v=I_4z5HMq5EE\&app=desktop. Acesso em: 18 mar 2020.
} 


\section{CONSIDERAÇÕES FINAIS}

A educação como forma de desenvolvimento humano deve valorizar o indivíduo, dando-o autonomia e o empoderando para que possa gozar de todas as liberdades instrumentais. A falha do ensino educacional padronizado não recai apenas sobre a graduação, mas a todo o sistema que desde o ensino fundamental molda os alunos a seguirem uma linha de raciocínio tecnicista. Por isso a importância de um movimento que estimule o acesso do indivíduo às habilidades do Século XXI. Questões como empatia, liderança, adaptabilidade, tomada de decisões, empoderamento do outro, autonomia e facilidade para conexões interpessoais passarão a ser mais notáveis no ambiente de trabalho, causando uma sobrevalorização dos trabalhos coletivos aos individuais, por estarem atrelados a uma pluralidade de habilidades e inteligências múltiplas. A capacidade de atrelar processos criativos à prática profissional também será um dos principais fatores de desenvolvimento laboral deste século, pois será ela que diferenciará o trabalho humano do automatizado e promoverá inovações aos diferentes setores da política, sociedade e do mercado.

Nesse sentido, as tendências educacionais a nível superior para a advocacia atendem a uma sinergia entre gestão e aspectos pedagógicos, desenvolvendo metodologias de ensino que se conectem a inovações e tecnologias pelas quais o mercado jurídico vivencia e se propõe a absorver. Apresenta-se, assim, o relato de experiência do programa Líderes que Transformam, idealizado e implementado desde 2012 na Pós-Graduação da Universidade de Fortaleza.

Os resultados alcançados pelo programa representam uma alternativa bem sucedida ao modelo tradicional de ensino jurídico, favorecendo a valorização e o desenvolvimento das múltiplas inteligências descritas por Gardner e adotando um modelo educacional que permite o protagonismo do estudante, conforme proposto por Freire. Ao adotar os ODS como vetor norteador do TCCs, o programa conecta os alunos às necessidades globais, estimulando-os a agir localmente e os posicionando como cidadãos responsáveis pela transformação social.

Acredita-se, dessa forma, que os alunos egressos deste modelo educacional, além de estarem preparados para ingressar e ascender profissionalmente no mercado de trabalho frente aos desafios do contexto atual, responderão às demandas sociais, atuando como cidadãos globais e lideranças em suas comunidades.

\section{REFERÊNCIAS}

CEPI FGV Direito. Executive Summary "Technology, legal professions and education" Quantitative Research. Disponível em: https://www.academia.edu/39575731/Executive_Summary_TECHNOLOGY_LEGAL_PROFESSIONS _AND_EDUCATION_Quantitative_Research. Acesso em 18 fev, 2020. 
CEPI FGV Direito. Executive Summary "Technology, legal professions and education" Qualitative Research. Disponível

em: https://www.academia.edu/39575730/Executive_Summary_TECHNOLOGY_LEGAL_PROFESSIONS _AND_EDUCATION_Qualitative_Research. Acesso em $18 \mathrm{fev}, 2020$.

CHRISTEMSEM, Clayton M.; EYRING, Henry J. A universidade inovadora: mudando o DNA do ensino superior de fora para dentro. Tradução de Ayresnede Casarin da Rocha. Porto Alegre: Bookman, 2014.

COUTINHO, Sonia Maria Viggiani; et al. Contextos Criativos: potencializando a institucionalização de interdisciplinaridade na graduação. . IN: JÚNIOR, Arlindo Philippi; FERNANDES, Valdir; PACHECO, Roberto C.S. Ensino, pesquisa e inovação: desenvolvendo a interdisciplinaridade. São Paulo: Manole, 2017.

FGV Direito SP. Centro de Ensino e Pesquisa em Inovação (CEPI). Disponível em: https://direitosp.fgv.br/centro-de-pesquisa/centro-de-ensino-pesquisa-inovacao. Acesso em 17 fev, 2020.

FGV Direito SP. Disciplinas Eletivas.Disponível em: https://direitosp.fgv.br/disciplina/disciplinaseletivas. Acesso em $17 \mathrm{fev}, 2020$.

FGV Direito SP. Observatório do Ensino do Direito.Disponível em: https://direitosp.fgv.br/observatorioensino-direito. Acesso em 17 fev, 2020.

FOLHA de São Paulo. Ranking Universitário Folha, 2019. Disponível em: https://ruf.folha.uol.com.br/2019/ranking-de-cursos/direito/. Acesso em: 14 fev, 2020.

FREIRE, Paulo. A pedagogia do oprimido.17. ed. Rio de Janeiro. Paz e Terra, 1987.

GARDNER, HOWARD etc al. Inteligências múltiplas ao redor do mundo.Tradução de Rogério de Castro Oliveira. Porto Alegre: Artmed, 2010.

GOMES, Elizabeth; BRAGA, Fabiane. Inteligência competitiva em tempos de Big Data: analisando informações e identificando tendências em tempo real. Rio de Janeiro: Alta Books, 2017.

HARVARD UNIVERSITY. Legal Research and writing program. Disponível em: https://hls.harvard.edu/dept/lrw/course-overview/. Acesso em 16 jun. 2019.

HARVARD UNIVERSITY. Problem Solving Workshop. Disponível em: https:/hls.harvard.edu/dept/academics/winter-term/problem-solving-workshop/. Acesso em 16 jun. 2019. 
IE LAW SCHOOL. Acerca de IE Law School. Disponível em: https://www.ie.edu/es/law-school/sobrenosotros/acerca-ie-law-school/. Acesso em 16 jun. 2019.

IE Law School. Reinventing Higher Education. Disponível em: https://www.ie.edu/es/law-school/sobrenosotros/acerca-ie-law-school/. Acesso em 16 jun. 2019.

LEVÝ, Jirí. The process of creation of a work of literature and its reception.Tradução de Patrick Corness. 1971. Disponível em: https://utrl.ff.cuni.cz/UTRLFF-400-version1-Geneze.pdf. Acesso em: 14 de jun. 2019.

MARTIN, Roger. Design de Negócios: por que o design thinking se tornará a próxima vantagem competitiva dos negócios e como se beneficiar disso. Tradução de Ana Beatriz Rodrigues. Rio de Janeiro: Alta Books, 2017.

MINDDRIVE. About Minddrive. Disponível em: https://minddrive.org/about. Acesso em: 13 jun, 2019.

OECD. Programme for International Student Assessment. Disponível em: https://www.oecd.org/pisa/publications/pisa-2018-results.htm. Acesso em 18 fev. 2020

PRADUROUX, Sabrina; PAIVA, Valeria de; CARO, Luigi di. Legal Tech Start-ups: State of the Art and Trends, 2016. Disponível em: http://vcvpaiva.github.io/includes/pubs/2016-legal.pdf. Acesso em: 10 jun. 2019.

ROBINSON, Ken. Escolas Criativas: a revolução que está transformando a educação. Tradução de Luís Fernando Marques Dorvillé. Porto Alegre: Penso, 2019.

ROSSINTELLIGENCE.ROOS. Disponível em: https://rossintelligence.com/. Acesso em: 10 jun. 2019.

SALES, Lilia Maia de Morais; BEZERRA, Mário Quesado Miranda. Os avanços tecnológicos do século XXI e o desenvolvimento de habilidades necessárias ao profissional do Direito a partir das abordagens das Universidades de Harvard e Stanford. IN: Revista Pensar, v. 23, n. 4, p. 1-13, 2018. Disponível em: https://periodicos.unifor.br/rpen/article/view/8016/pdf. Acesso em: 10 jun, 2019.

SEM, Amartya. Desenvolvimento como liberdade. Tradução de Laura Teixeira Motta. São Paulo: Companhia das Letras, 2010

SEMESP. Guia Framework de inovação para IES. Disponível em: https://www.semesp.org.br/publicacoes/guiainovacao. Acesso em 05 mar, 2020. 
Times Higher Education. Europe Teaching Rankings 2019.Disponível em: https://www.timeshighereducation.com/rankings/europe-teaching/2019\#!/page/0/length/1/sort_by/rank/sort_order/asc/cols/undefined. Acesso em 14 fev, 2020.

Times Higher Education. World University Rankings 2020. Disponível em: https://www.timeshighereducation.com/world-university-rankings/2020/worldranking\#!/page/0/length/25/sort_by/rank/sort_order/asc/cols/stats. Acesso em 14 fev, 2020.

UNIVERSITY OF STANFORD. Legal Research and Writing Program. Disponível em: https://law.stanford.edu/legal-research-and-writing-program/\#slsnav-fellowship-fellows. Acesso em 16 jun. 2019.

UNIVERSITY OF STANFORD. Writing Workshop: Law and Creativity. Disponível em: https://law.stanford.edu/courses/writing-workshop-law-and-creativity/. Acesso em 16 jun. 2019.

VICTORIA, Mara Sizino da; et al. Níveis de ansiedade e depressão em graduandos da Universidade do Estado do Rio de Janeiro (UERJ). IN: Revista de Psicologia, vol. 16, oㅡ 25, p. 163-175. São Paulo: Anhanguera Educacional, 2013.2 Disponível em: https://www.researchgate.net/publication/327121216_Niveis_de_ansiedade_e_depressao_em_gradu andos_da_Universidade_do_Estado_do_Rio_de_Janeiro_UERJ. Acesso em 13 jun. 2019.

WALDMAN, Helio; DALPIAN, Gustavo Martini. A universidade e a construção da interdisciplinaridade. IN: JÚNIOR, Arlindo Philippi; FERNANDES, Valdir;

WORLD ECONOMIC FORUM - WEF. The future of jobs report, 2018. Disponível em: http://www3.weforum.org/docs/WEF_Future_of_Jobs_2018.pdf. Acesso em 14 jun, 2019.

PACHECO, Roberto C.S. Ensino, pesquisa e inovação: desenvolvendo a interdisciplinaridade. São Paulo: Manole, 2017. 